\title{
A Preliminary Model for Quantifying the Risk of Rockfalls and Evaluating the Benefits of Safety Spending
}

\author{
W.C. Joughin SRK Consulting, South Africa
}

\begin{abstract}
Safety spending in the mining industry is often viewed as a necessary but expensive overhead cost. This mindset places safety and productivity in direct opposition to each other, while improved safety practices could actually lead to better productivity. Alternatively, from a pure safety perspective, the perception also exists that more is better in terms of safety spending, while the additional spending may not necessarily lead to a significant reduction in risk. In order to evaluate the real benefits of safety spending in mitigating rockfalls and their consequences a risk model is being developed as part of an ongoing SIMRAC research programme. A preliminary model has been developed and is presented in this paper. The model will enable the quantification of the likelihood of occurrence rockfalls under various conditions with different support systems. It will also allow the likelihood of occurrence of the various direct and indirect consequences of rockfalls to be determined. The effect of various monitoring and mitigating strategies can also be evaluated through the model. If the costs associated with these consequences are known, then the model can be used to determine the expected cost of rockfalls. The overall cost of a safety strategy can then be determined as the sum of the cost of implementing and maintaining the strategy and the expected cost of rockfalls with the strategy implemented. It will provide a method for designing according to tolerable levels of safety risk.
\end{abstract}

\section{Introduction}

Safety spending in the South African mining industry is often viewed as a necessary but expensive overhead cost. This mindset places safety and productivity in direct opposition to each other, while improved safety practices could actually lead to better productivity. Alternatively, from a pure safety perspective, the perception also exists that more is better in terms of safety spending, while the additional spending may not necessarily lead to a significant reduction in risk. Very often, the benefits of safety spending are expressed only in terms of reduced injury and fatality rates. The additional financial benefits of reducing rockfall rates are seldom quantified and the indirect, downstream benefits are often not recognised or acknowledged.

In order to evaluate the real benefits of safety spending in mitigating rockfalls and their consequences, a risk model is being developed as part of an ongoing SIMRAC research programme. One of the aims of this research is to demonstrate the financial benefits of safety spending and to provide tools for quantifying this benefit under various conditions. The financial benefits can be viewed as an additional motivation for improving safety. The safety risk can be quantified and benchmarked, in order to define risk targets or minimum criteria for design purposes. It is intended to implement the risk model in a computer program which can interactively compare and quantify the benefit of safety spending for different scenarios. A preliminary risk model is presented in this paper.

\section{Risk evaluation process}

Risk evaluation processes for rock engineering have been described in Terbrugge et al. (2006), Stacey et al. (2007) and Stacey (2007) and an evaluation process for underground stopes is presented in Figure 1. The first part of the process involves the evaluation of the reliability of the design, which is the probability of failure (occurrence of rockfalls). Rockfalls can occur under different circumstances and methods for determining the likelihood of occurrence of rockfalls of different sizes are discussed in Section 4.

Secondly event trees are developed to determine the risks associated with a number of different consequences. These event trees incorporate the concepts of exposure, spatial coincidence, monitoring and evacuation and the process of evaluating the probability of occurrence of these consequences is discussed in 
Section 5. The risk is the product of the probability of occurrence and the consequence and these results can then compared with accepted risk levels as indicated in Figure 1.

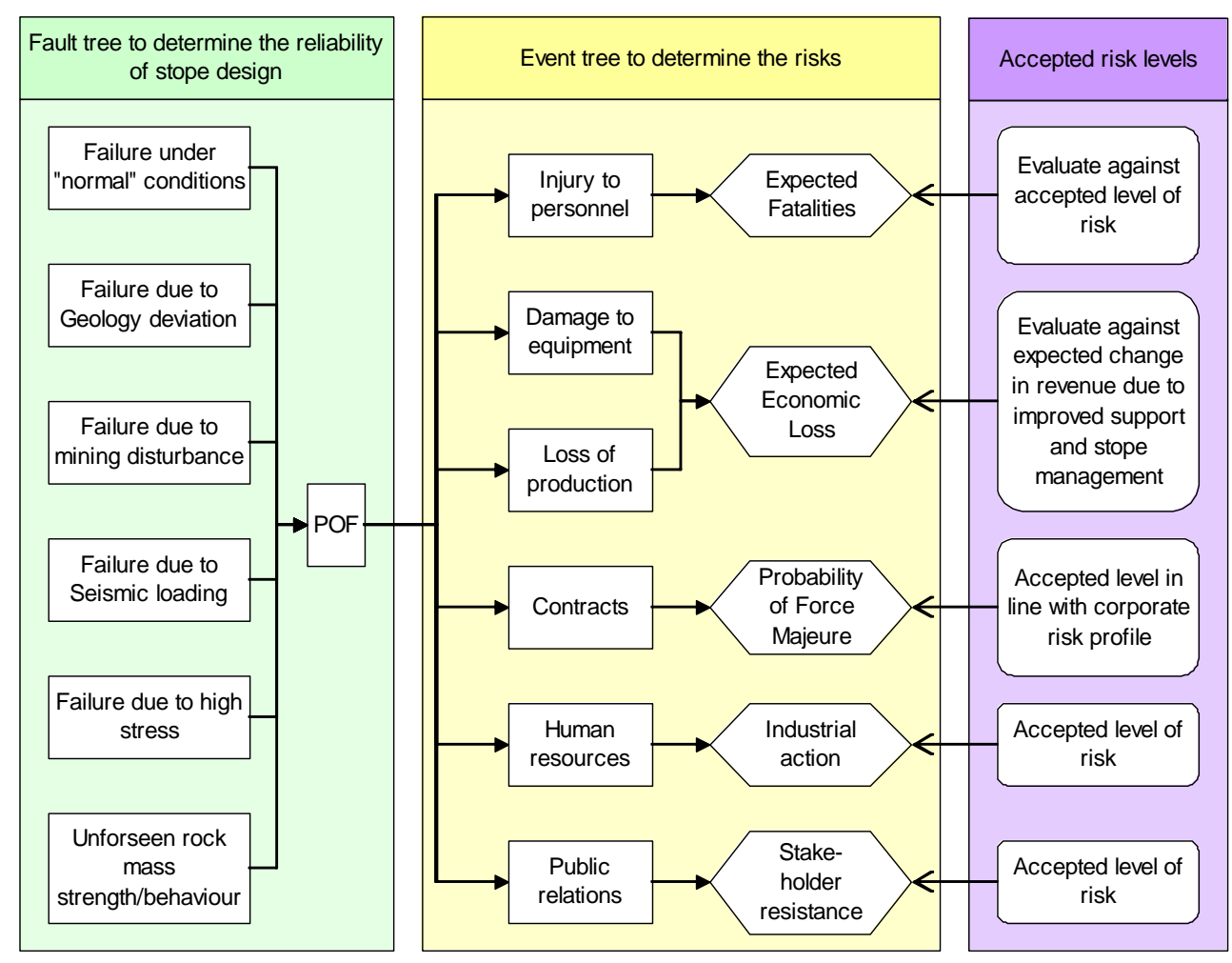

Figure 1 Risk evaluation process (after Stacey et al., 2007)

Of all the risks, determining the tolerable or acceptable risk of a fatality arising from a rockfall, for design purposes, is the most controversial. Most companies target zero fatalities. While this is certainly a mission, it is not realistic to design for zero fatalities. In the nuclear power generation and dam engineering industries acceptable risks are defined, based on societal norms, and designs are made to comply with these. The F-N graph (Figure 2(a)) is typically used for evaluating and benchmarking the risk of a fatality. It is plotted as the number of fatalities from accidents versus the annual probability of exceeding that number. The areas in the graph indicating tolerability of risk are derived from risk guidelines developed in the United Kingdom. The graph also contains fatality criteria developed in dam engineering (British Columbia (BC) Hydro, Netherlands, Hong Kong), which is of interest because it is based on a conservative approach, since dam failures can be so devastating. The local tolerability line defines the lower boundary of a region which is characterised by both high frequencies and severe consequences (the intolerable region). The region between this line and the local scrutiny line is a region of possibly unjustifiable risk. The negligibility line defines the upper boundary of a region, in which all combinations of frequency and number of fatalities are negligible. The 'as low as reasonably practicable' (ALARP), represents a region which is judged to be tolerable, but for which all reasonably practicable steps should be taken to mitigate the hazard further (Contreras et al., 2006; Terbrugge et al., 2006). Terbrugge et al. (2006) present the risk profiles of various industries, plotted on the F-N graph and provide comparative fatality statistics for travel, dangerous employment, dangerous sports, lifestyle, dread disease, general accidents and natural hazards. The F-N graph provides a tool for benchmarking and defining the acceptable risk of a fatality. Goals can be set and designs can be adapted to achieve these goals.

The expected costs (probability x cost) of production and equipment losses should be compared with the cost of implementing an improved support system or safety strategy. The optimal strategy represents the lowest combined cost as illustrated in Figure 2(b). It is proposed that the costs of the support strategy are evaluated on annual basis, so that this can be compared with the annual probability of occurrence of rockfalls and their associated consequential costs. This allows the same process of determining the probability of occurrence of rockfalls to be applied to both the calculation of expected fatalities and the economic loss. 
The probability of occurrence of the consequences of force majeure, stakeholder resistance and industrial action in Figure 1 are more difficult to calculate and will require considerable judgement to evaluate.

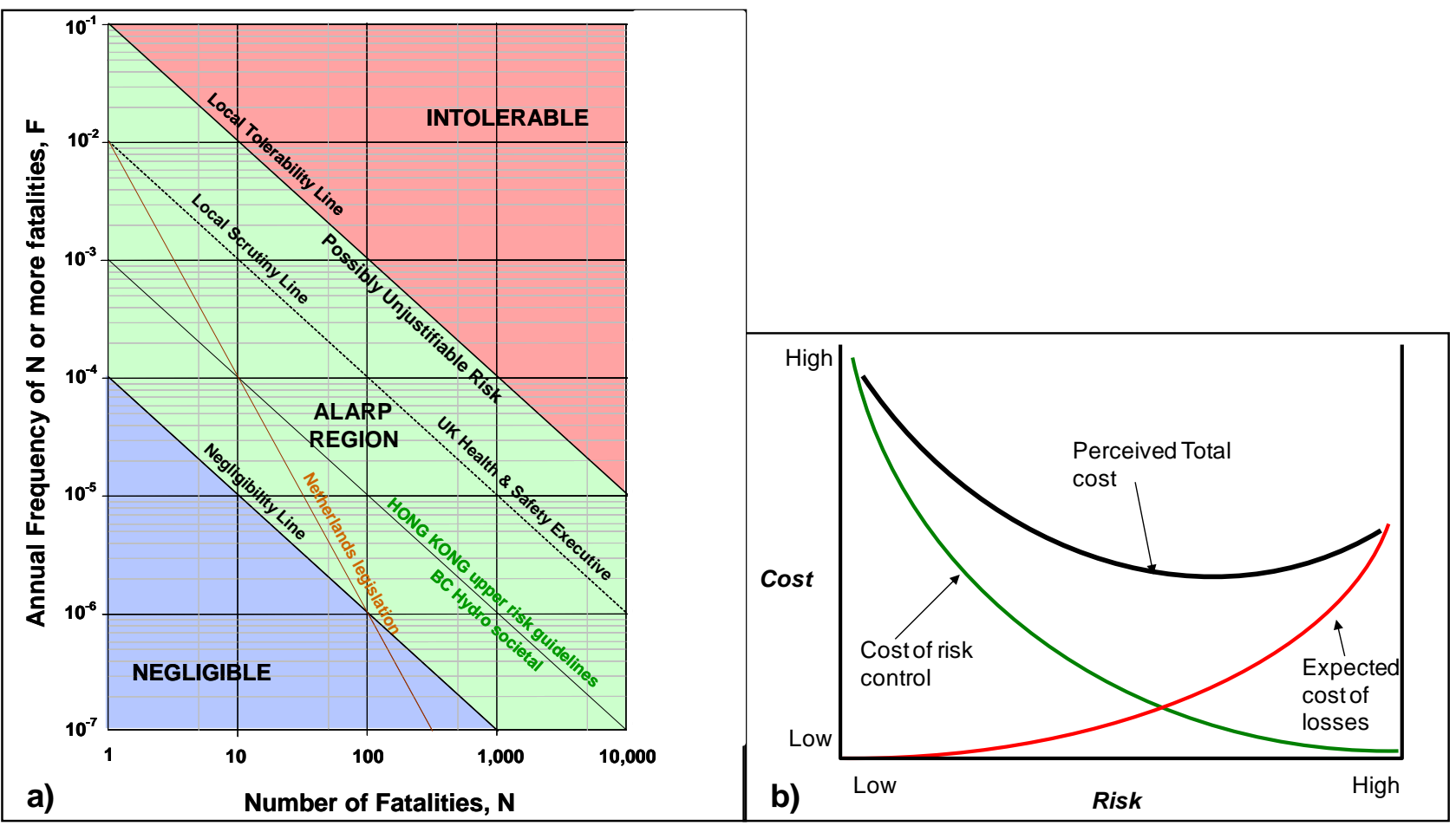

Figure 2 Acceptable risk a) F-N graph for benchmarking safety impact (after Contreras et al., 2006); b) cost versus risk relationship

\section{Safety strategies and support systems}

In this section, different safety strategies and support systems, which could be evaluated using the risk model, are discussed. It must be possible to determine an annual cost of the safety strategy or support system, including implementation costs, and that of the existing strategy or support system, or at least the difference in annual costs. The expected injuries, economic losses and other consequences should be determined using the risk model. The benefits of implementing some of these safety strategies and support systems could be evaluated mathematically using the methods described in Sections 4 and 5, while others will require some degree of judgement to evaluate the benefits.

\subsection{Mining methods and layouts}

The choice of mining method can significantly influence the risk profile and economics of a mining operation. Mechanised mining methods invariably reduce the exposure of personnel and can substantially reduce the risk of fatal injuries. Often the risk of damage to machinery is increased, but can be justified economically.

Excavations deteriorate with time and the probability of occurrence of additional and larger rockfalls increase with time. Proper scheduling of mining can prevent rockfalls or limit the exposure of men and machinery. This can result in a reduction in mining flexibility and may require additional development at greater cost to counteract this.

The dimensions of stopes, tunnels and pillars can have a significant influence on the probability of occurrence of rockfalls. In shallow mines, larger tunnels and stopes are likely to have more and larger rockfalls, due to the lack of confining stresses and allowing space for larger blocks to form. While in deeper mines, stress fracturing becomes more prevalent and rockbursts are more frequent with increasing spans. 
The risk model could be used to compare different mining methods and layouts, but the evaluation process will be complex, requiring a detailed trade off study to determine both the operating costs and overall risk profile.

\subsection{Support systems}

For the same geotechnical conditions and mining layout, alternative support systems can mitigate the risk of fatal injuries and damage to equipment substantially. Some products have greater load capacity or the ability to deform, while maintaining load under dynamic conditions. Other products provide improved surface coverage in between support. The cost of support systems can be easily evaluated taking into account material costs, transport and installation costs. The material cost is often less than half of the total installed cost in typical labour intensive and extensive tabular South African mines, which is often overlooked.

The probability of occurrence of rockfalls and associated consequences could be evaluated using the model. All other aspects of the model could be kept constant, so that only the effect of changing the support system can be evaluated rigorously.

\subsection{Monitoring systems}

Monitoring systems can be used to provide information for mining layout and support design, which will reduce the probability of occurrence of rockfalls. More sophisticated monitoring systems could possibly allow the evacuation of personnel in the event of an imminent rockfall. In this way, the risk could be substantially reduced. These monitoring systems are however, in the development phase, but their perceived benefits could be evaluated through a risk model. Evaluation of the benefits will require some degree of judgement, since it is difficult to obtain data to verify the perceived improvements. A summary of monitoring systems, their functions and how they can be used to mitigate risk is listed in Table 1.

Table 1 Summary of monitoring systems

\begin{tabular}{|c|c|c|c|}
\hline Monitoring systems & Examples & Function & $\begin{array}{l}\text { Performance and Risk } \\
\text { Evaluation }\end{array}$ \\
\hline $\begin{array}{l}\text { Rock } \\
\text { characterisation }\end{array}$ & $\begin{array}{l}\text { GPR, borehole radar, borehole } \\
\text { camera, acoustic televiewer, } \\
\text { sounding device, acoustic } \\
\text { energy meter, joint mapping, } \\
\text { rock mass classification. }\end{array}$ & $\begin{array}{l}\text { To determine joint characteristics, rock } \\
\text { mass characteristics and identify } \\
\text { geological structures. }\end{array}$ & $\begin{array}{l}\text { Evaluate risk by improving } \\
\text { layout and/or support design. }\end{array}$ \\
\hline $\begin{array}{l}\text { Instruments to } \\
\text { measure deformation } \\
\text { and load }\end{array}$ & $\begin{array}{l}\text { Extensometers (rod, wire, } \\
\text { magnesonic), closure meters } \\
\text { (spring verniers, wire pull } \\
\text { meter, telescopic), support load } \\
\text { cells (prop, rockbolt). }\end{array}$ & $\begin{array}{l}\text { To determine rock mass behaviour, } \\
\text { performance of support systems and } \\
\text { mining layouts. }\end{array}$ & $\begin{array}{l}\text { Evaluate risk by improving } \\
\text { layout and/or support design. }\end{array}$ \\
\hline $\begin{array}{l}\text { Integrated } \\
\text { monitoring systems }\end{array}$ & $\begin{array}{l}\text { GoafWarn/FOGWarn, AziSA } \\
\text { (Brink and Roberts, 2007), } \\
\text { Destiny, Rockwatch (Piper and } \\
\text { Malan, 2008). }\end{array}$ & $\begin{array}{l}\text { To determine rock mass behaviour and } \\
\text { performance of support systems and } \\
\text { mining layouts comprehensively in real } \\
\text { time. To provide early warnings of } \\
\text { potential rockfalls. }\end{array}$ & $\begin{array}{l}\text { Evaluate risk by improving } \\
\text { layout and/or support design. } \\
\text { Possible scope for evacuating } \\
\text { personnel. }\end{array}$ \\
\hline $\begin{array}{l}\text { Integrated seismic } \\
\text { monitoring systems }\end{array}$ & ISSi, ESG, Prism. & $\begin{array}{l}\text { To determine rock mass behaviour and } \\
\text { performance of mining layouts } \\
\text { comprehensively in real time. To } \\
\text { provide early warnings of potential } \\
\text { rockbursts. }\end{array}$ & $\begin{array}{l}\text { Evaluate risk by improving } \\
\text { layout and/or support design. } \\
\text { Possible scope for evacuating } \\
\text { personnel. }\end{array}$ \\
\hline
\end{tabular}

\subsection{Quality control}

Timber support products that are commonly used in South African mines are quite variable in their performance. They also dry out if stored in the sun on surface, which reduces their performance. Regular testing, both in the laboratory and underground, allows the variability to be determined, so that the support system can be properly designed. Procedures for the storage and transport need to be implemented to ensure that the performance does not deteriorate. 
Support products often contain multiple components and poor performance of any of the components, could lead to a reduction in the overall performance. Quality control in the factory is critical to mitigate the likelihood of occurrence of reduced performance. This usually increases the cost of the support product.

A few South African mines have employed stope observers to carry out quality control on support installation. These semi-skilled employees are trained to install the relevant support correctly according to the suppliers' instructions and mine standards. They audit the stope panels frequently (once or twice a month) and record information on the quality of installation. During the audit, on the job training is provided to rectify any poor installations. Audit reports are presented to the line supervisors the same day and they are required to provide action plans, with dates, for remediation. All of this is captured in a database, which allows performance to be tracked. The cost of employing staff, implementing and maintaining this management system is quite substantial, but these costs could be outweighed by reduced rockfalls and improved production.

Where effective quality control systems are in place, the variability in support performance can be quantified. It must be assumed that where there is no system in place, the variability in support performance is high. The risk model could be used to calculate the reduction in probability of occurrence of rockfalls due to the reduced variability in support system performance. This could demonstrate that the implementation of quality control systems can reduce the expected costs associated with rockfalls and possibly offset the increased cost, while reducing the risk of fatal injuries.

\section{Determination of the probability of occurrence of rockfalls}

In this section, rockfalls in South African mines are analysed and this information is then applied to methods of calculating the probability of occurrence of rockfalls.

\subsection{Distributions of rockfall dimensions}

Several South African mines have been compiling comprehensive rockfall databases, which are particularly useful for determining statistical distributions of rockfall dimensions. While other pertinent information is contained in the databases, the structure of the databases varies and it is difficult to obtain useful statistics on types of rockfalls and modes of failure.

A total of 810 rockfall records were obtained from several mine rockfall databases, representing approximately 1000 stope panels, over a three year period. These range in size from less than 0.5 to almost $4000 \mathrm{~m}^{3}$. Frequency distributions of rockfall area and volume are presented in Figure 3. The distribution of rockfall area is important to determine the likelihood of a rockfall causing an injury or damage to machinery (spatial coincidence, Section 5.2.3). Small rockfalls are more common, but each small rockfall is less likely to injure a person or strike a machine than a large rockfall.

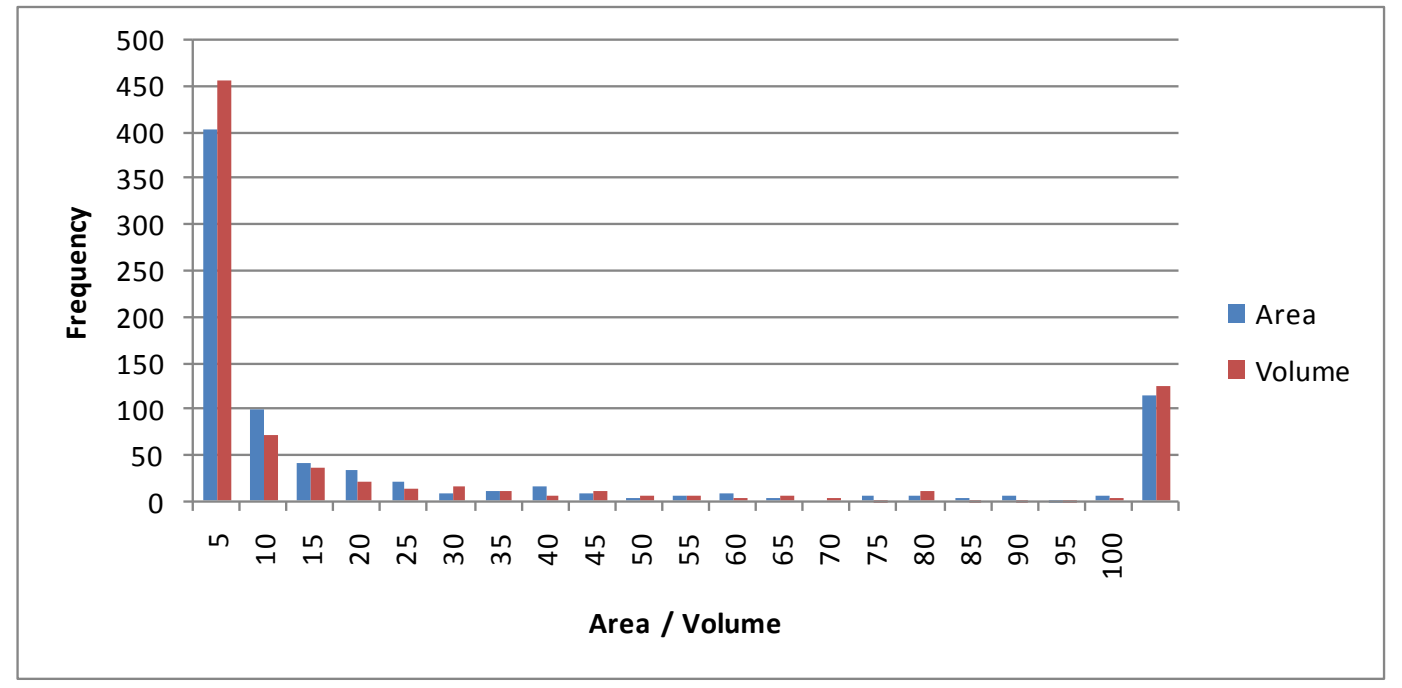

Figure 3 Frequency distribution of rockfall area and volume determined from three years of rockfall data collated by South African Platinum mines 
In Figure 3, $5 \mathrm{~m}^{2}$ and $5 \mathrm{~m}^{3}$ bins were used to determine the distributions up to a maximum of $100 \mathrm{~m}^{2}$ and $100 \mathrm{~m}^{3}$. Approximately $50 \%$ of the rockfalls are less than $5 \mathrm{~m}^{2}$ and $5 \mathrm{~m}^{3}$, while almost $15 \%$ of the rockfalls were in excess of $100 \mathrm{~m}^{2}$ or $100 \mathrm{~m}^{3}$. The full range of rockfall areas and volumes cannot be presented clearly using small enough bins to represent the small rockfalls. An equivalent radius, assuming a circular area, was calculated for each rockfall to get around this problem. The frequency distribution and cumulative frequency distribution of equivalent rockfall radius is shown in Figure 4. Power and exponential curves were fitted to the cumulative frequency distribution, which are both good fits. The exponential curve has a higher correlation coefficient, but the power curve accounts for the lack of data for small rockfalls.

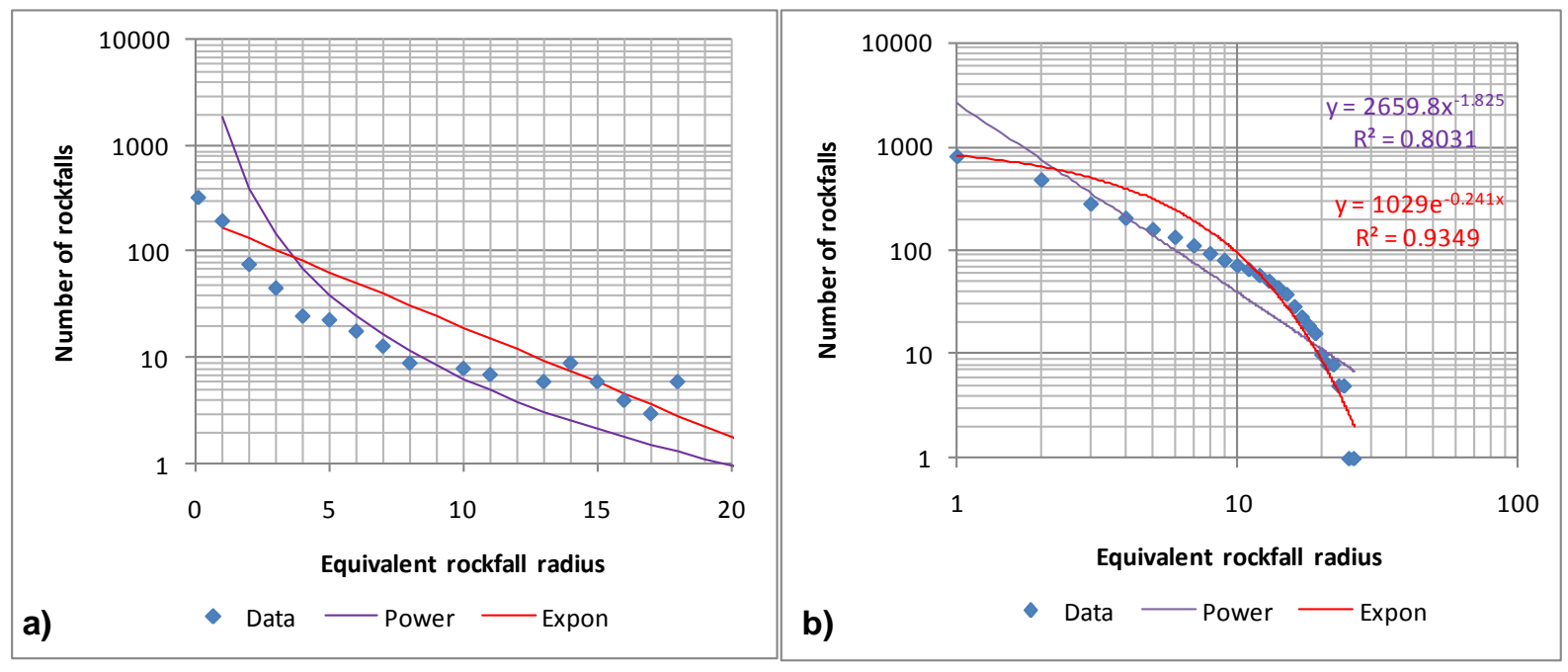

Figure 4 a) Frequency distribution; b) cumulative frequency distribution of equivalent rockfall radius determined from three years of rockfall data collated by South African Platinum mines

\subsection{Methods of calculating the probability of occurrence of rockfalls}

The probability of occurrence of rockfalls can be determined using rock mass classification methods or analytical methods. These methods and the merits of using them are discussed in this section.

\subsubsection{Rock mass classification methods}

Rock mass classification methods, such as the Q system (Barton et al., 1974), modified stability number N' (Potvin, 1998; Potvin and Hadjigeorgiou, 2001) and mining rock mass rating (MRMR) (Laubscher, 1990), are used to determine the stability of stopes and tunnels and the required support. These ratings are compared with the hydraulic radius or span of an excavation, to determine potential stability using empirical curves. The input parameters are determined from geotechnical mapping or borehole logging. When sufficient data has been obtained, there will be considerable variability in each of the input parameters, which can be represented by fitted probability distribution. A Monte Carlo simulation or point estimate method simulation (Rosenblueth, 1975; Harr, 1987) can then be carried out using randomly generated values from the distributions of each input parameter and a probability distribution can be obtained for the Q, N' or MRMR. Hutchinson and Diederichs (1998) describe this approach in their book on cable bolting. The probability of failure for a given stope dimension can be determined.

However, failure could mean a few rockfalls or the unravelling of the entire stope back. It is not possible to determine the size or number of rockfalls, that could be expected from a given stope/tunnel geometry. It will therefore not be possible to determine the extent of damage or evaluate the spatial coincidence (Section 5.2.3). The approach could be used to evaluate stope scale effects and indicate an increased probability of occurrence of rockfalls, in conjunction with analytical models. 


\subsubsection{Analytical models}

Several analytical models have been developed to design stope layouts and support. These involve calculating the demand and capacity and determining a factor of safety. The input parameters are variable and probability distributions of each of these parameters can be determined through investigation. Where there is adequate data, probability distributions are fitted to the data, but simple triangular or uniform distributions can also be determined when there is limited information. Using the model and carrying out a Monte Carlo simulation or point estimate method simulation (Rosenblueth, 1975; Harr, 1987), a distribution of factors of safety can be determined. A factor of safety of less than 1.0 indicates failure. The probability of failure is simply the probability of the factor of safety being less than 1.0.

Rockfalls can occur as a result of different mechanisms in the same excavation and the probability of occurrence is the sum of all the probabilities of failure for each failure mechanism, except where the occurrence of one event precludes the occurrence of other mechanisms.

Analytical models applicable to the design of stopes in shallow South African mines are summarised by Swart et al., 2000. These describe most of the rockfall mechanisms and are included here.

\subsubsection{Keyblocks}

Keyblocks are probably the most common type of rockfall that occurs in South African mines. Blocks can be bounded by joints, bedding planes, curved joints (thrusts, domes and cross bedding), faults or stress fractures. The blocks vary in size and shape depending on the interaction between these discontinuities.

Software has been developed (Grenon and Hadjigeorgiou, 2003; Esterhuizen, 2003) to analyse keyblocks using joint networking and limit equilibrium methods. The software JBlock (Esterhuizen, 2003) has been used by several authors to analyse keyblock stability (Esterhuizen and Streuders, 1998; Joughin et al., 2006; Dunn et al., 2008; Stacey, 2007).

JBlock was developed to evaluate the potential for gravity driven rockfalls to occur in mining excavations. It can be used to test sensitivity of keyblock failure to support capacities and spacing. Where stress fractures form parallel to the excavation abutments, the effect of orientation of the excavation on the interaction of joints and stress fractures can be tested. The program makes use of statistical methods to simulate keyblocks in the hangingwall from joint data. Blocks with four to six faces, with the hangingwall forming the lower face, can be simulated. Block removability is determined using methods developed by Goodman and Shi (1985). Once a keyblock has been identified, it is placed at random positions in a pre-defined excavation, with support, and checks whether the keyblock is located over support units. Blocks can fail in between supports, or if the capacity of the supports is exceeded, or in rotational mode. Horizontal clamping stresses can be simulated, which could be used to simulate regional effects. Several thousand keyblocks can be simulated and evaluated at random positions within the excavation and histograms of the probability of failure of keyblocks of different sizes are produced.

An example of the results of a simulation of 10,000 keyblocks, determined using a combination of joint sets for a typical South African Bushveld Complex mine geotechnical area, is presented in Figure 5. JBlock determines a frequency histogram of block sizes and the probability of failure in between supports or due to support failure. The probability distribution is obtained by taking the number of blocks in each bin and dividing by the total number of keyblocks formed. The probability of occurrence is plotted on a log scale, since more than $60 \%$ of the blocks formed are less than $5 \mathrm{~m}^{3}$ and less than $1 \%$ falls into many of the remaining bins. Small keyblocks invariably fail by falling in between supports, while larger blocks tend to exceed the capacity of the support. Only very slender geometries can fail in between support, if the block size is greater than $5 \mathrm{~m}^{3}$ and there are no failures in between support when the block size exceeds $55 \mathrm{~m}^{3}$. The histogram of block failures is determined by multiplying the frequency histogram of all blocks by the combined probability of failure (in between support and support failure) and dividing by the total number of simulated blocks. This is done to demonstrate the proportion of blocks that fail for each bin.

The probability distribution of rockfalls is determined by calculating the frequency of occurrence of block failures and dividing by the total number of block failures (as opposed to the total number of simulated blocks) and is shown in Figure 6. Comparing the results with actual rockfall data (Figure 3), the trends are similar. However, $80 \%$ of the rockfalls are less than $5 \mathrm{~m}^{3}$ in Figure 6, compared with $50 \%$ of the rockfalls in 
Figure 3. It is likely, that the distributions generated by JBlock are realistic and despite the diligence applied in collating the rockfall data, it is simply not possible to obtain a representative sample of the smaller rockfalls.

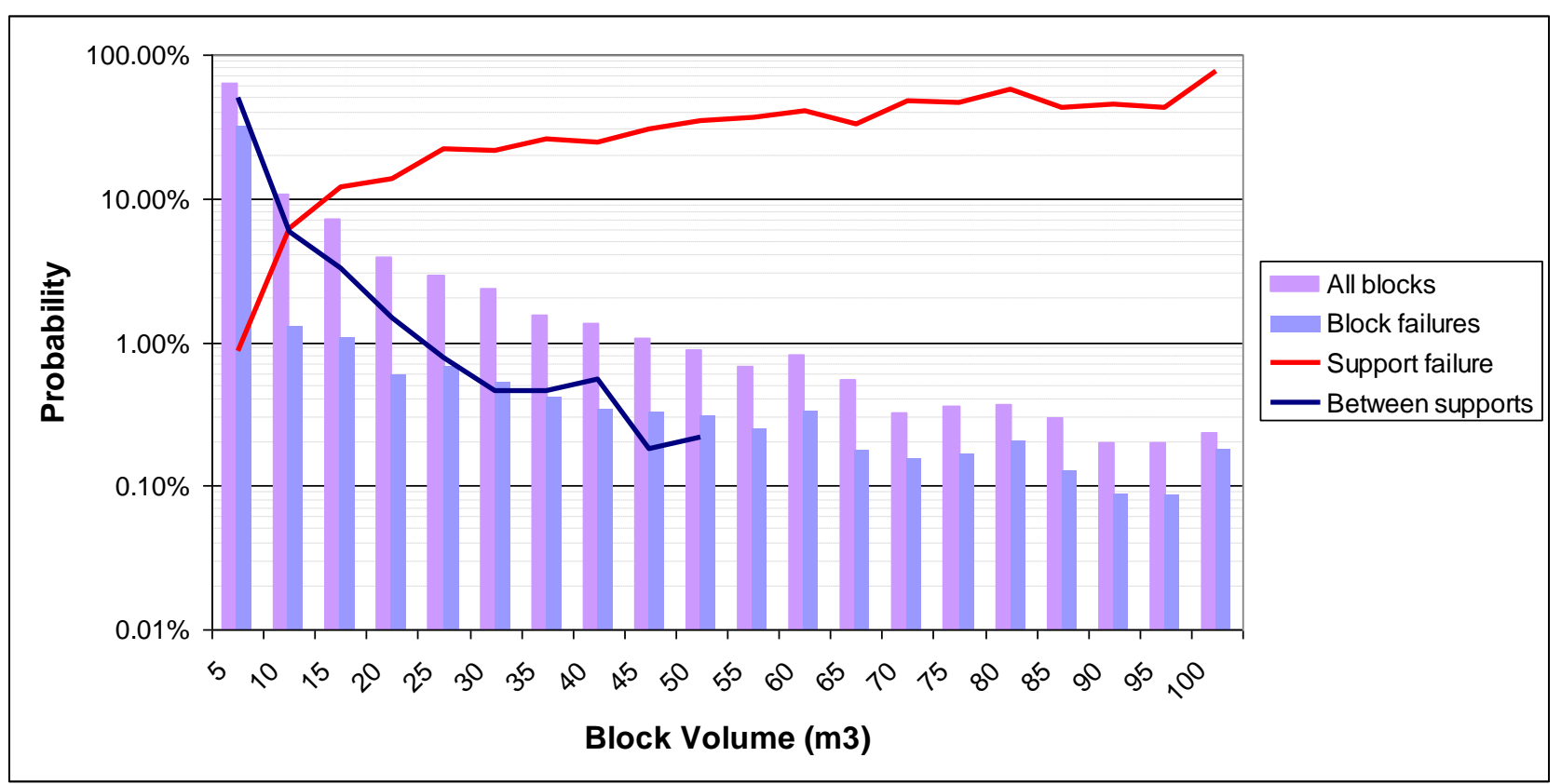

Figure 5 Probability distribution of simulated blocks and modes of failure calculated by JBlock

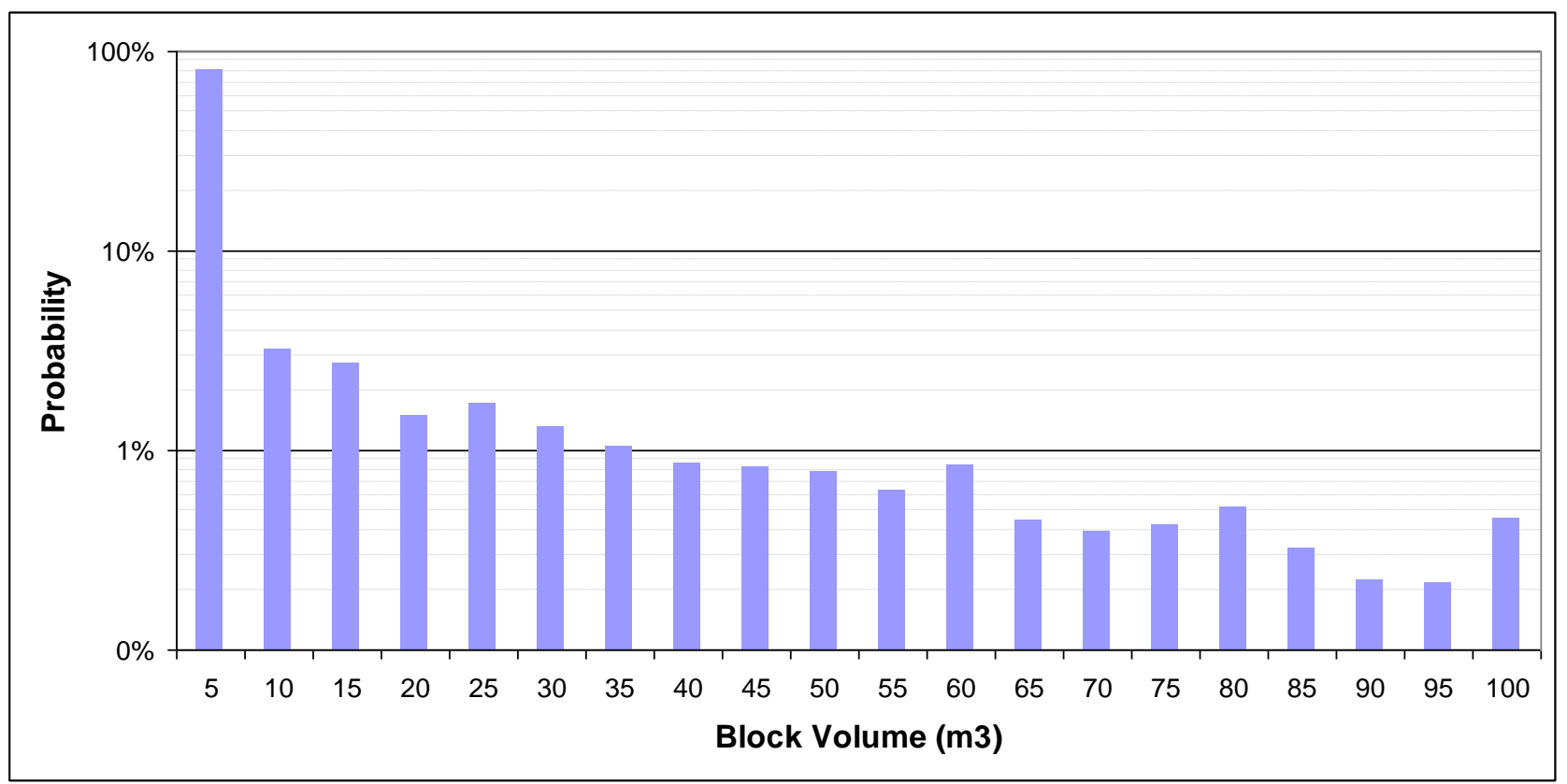

Figure 6 Probability distribution of simulated rockfalls determined from JBlock

JBlock is a useful tool to determine distributions of the size of rockfalls for different geotechnical conditions and support types, which is critical for calculating spatial coincidence (Section 5.2.3). This tool could easily be enhanced to provide probability distributions of an equivalent radius as shown in Figure 4, which would allow the entire range of rockfall sizes to be represented. Further enhancements would include allowing variable joint shear strengths to look at changing conditions and introducing variability in support spacings and capacities to test quality control. 
A further limitation is that JBlock simply simulates a stipulated number of keyblocks and tests the stability of the blocks. It does not determine how frequently keyblocks will form under a given set of conditions. This is necessary to calculate the annual frequency of occurrence of rockfalls, which is required to determine spatial coincidence (Section 5.2.3). This will need to be developed.

\subsubsection{Beam models}

Elastic beam theory is well developed and is useful for explaining the deformation and failure of the hangingwall in laminated strata. It is, however, limited to geotechnical areas where sub-vertical or inclined joints do not cross the laminations, eliminating the tensile strength of the beam. It has applicability and is widely used in South African coal mines, where unjointed, laminated shale occurs in the immediate hangingwall. The input parameters include the thickness of loose strata (effective tendon length), density of the rock, excavation span and rock shear and tensile strength. The influence of changing tendon length and excavation span on the stability of excavations for varying rock mass conditions can be determined. The efficiency in beam building can be determined investigating the applied tendon load and shear strength of the layers. The effectiveness of a support system and its variability could be tested for different rock mass conditions.

Where sub-vertical joints are prevalent, the Voussoir beam model (Diederichs and Kaiser, 1999; Brady and Brown, 2006) can be used to investigate beam stability. The model assumes that a compressive arch is formed within the beam, which stabilises a jointed hangingwall. The beam can fail by crushing, buckling or in shear at the abutments. Support system performance and variability could be tested for different excavation spans under varying rock mass conditions.

For these beam models, it must be assumed that the rockfall will occur over the full span of the excavation. The excavation could be divided into representative unit lengths, which represent a face advance increment. The number of unit areas to be considered in one year will be the annual face advance divided by the face unit length. The annual frequency of rockfalls can be determined by multiplying the probability of failure by the number of unit areas.

\section{Evaluation of the consequences of a rockfall}

In this section, the direct and indirect consequences of rockfalls are discussed, event trees are developed and the concepts of exposure, spatial coincidence and evacuation are discussed.

\subsection{Direct and indirect consequences of rockfalls}

A summary of direct and indirect costs is presented in Table 2. The factors to consider when evaluating the consequences are described. All costs should be worked out as annual costs. The cost of the consequences should be determined and multiplied by the probability of occurrence of rockfall damage or injuries in one year to determine the expected cost.

In the case of injuries and fatalities there are significant costs incurred in addition to the moral and societal risk. In particular, temporary mine closures imposed after fatal accidents represents a substantial cost, since there is no revenue generated during the time of closure.

Production losses can be evaluated as the reduction in expected profit as a result of an incident, which is the revenue gained less variable costs (costs of explosives, support etc., which would not be spent if mining does not take place). If this model is applied, then any loss in reserves should be quantified by determining the NPV of those reserves, if they were extracted at the end of the life of the mine. Rehabilitation costs should be based on the typical costs of rehabilitating damaged excavations. The importance of the excavation should be taken into consideration.

Equipment repair cost should be based on typical repair costs for rockfall damage incidents. Where the damage is excessive or the repair cost exceeds the depreciated value of the equipment, it should be replaced. Replacement costs should be based on the depreciated value of the damaged equipment. 


\subsection{Event tree models}

Event trees have been developed for the three major consequences of rockfalls (Table 2). In each event tree, it is assumed that several rockfalls occur in an excavation during one year. The number and distribution of rockfalls could be determined using the analytical models or rockfall data discussed in Section 4.

The damage to excavations event tree model differs from the other two models, because a rockfall in an excavation implies damage, only the severity and location of damage need to be considered.

\section{Table 2 Summary of the direct and indirect consequences of rockfalls}

\begin{tabular}{|c|c|}
\hline Direct Consequences & Indirect Consequences \\
\hline \multirow{11}{*}{ Injuries and fatalities } & Excessive individual risk exposure for personnel (evaluate risk on F-N graph - set criteria and targets). \\
\hline & $\begin{array}{l}\text { Temporary mine closure imposed by the Department of Minerals and Energy (Section 54) - (revenue } \\
\text { from lost production less variable costs) up to } 5 \text { days of partial or full mine closure. }\end{array}$ \\
\hline & Medical and rescue operation costs. \\
\hline & Wages and compensation. \\
\hline & Investigation and inquiries - cost of professional time. \\
\hline & Re-training - cost of re-training new employees. \\
\hline & SIMRAC levies - (depends on severity of injury). \\
\hline & Legal costs - (determined from precedent practice). \\
\hline & Insurance premiums - (increase due to accident record). \\
\hline & Industrial action - difficult to quantify. \\
\hline & Stakeholder resistance (reputation, share price and cost of capital) - difficult to quantify. \\
\hline \multirow{4}{*}{$\begin{array}{l}\text { Damage to equipment } \\
\text { and machinery } \\
\text { (mobile and fixed) }\end{array}$} & $\begin{array}{l}\text { Loss of production (revenue from lost production less variable costs) if there is no alternate source of } \\
\text { production - only production affected by equipment loss. }\end{array}$ \\
\hline & Cost of re-deployment of machinery and personnel to maintain production. \\
\hline & Replacement costs (based on depreciated value of damaged machinery) - large rockfalls. \\
\hline & Cost of repairs - depends on extent of damage (size of rockfall). \\
\hline \multirow{10}{*}{$\begin{array}{l}\text { Damage to } \\
\text { excavations } \\
\text { (access excavations } \\
\text { and stopes) }\end{array}$} & $\begin{array}{l}\text { Loss of reserves (net present value of lost reserves less insurance claim) - major damage or loss of } \\
\text { access to stopes. }\end{array}$ \\
\hline & $\begin{array}{l}\text { Loss of production (revenue from lost production less variable costs) if there is no alternate source of } \\
\text { production. }\end{array}$ \\
\hline & Replacement of access excavations (cost divided by life in years) - large rockfalls. \\
\hline & Rehabilitation - proportional to size of rockfall and importance of excavation. \\
\hline & Dilution (in stopes). \\
\hline & Re-deployment of machinery and personnel to maintain production. \\
\hline & Clean up operations - depends on size of rockfall. \\
\hline & Insurance premium. \\
\hline & $\mathrm{s}-$ (increase due to claims). \\
\hline & Stakeholder resistance (reputation, share price and cost of capital) - difficult to quantify. \\
\hline
\end{tabular}

\subsubsection{Determination of exposure}

Personnel and equipment are not exposed all the time in the risk area where falls of ground occur and corrections need to be made to account for this.

The exposure of personnel can be determined as follows (use personnel with greatest exposure for analysis):

$$
\begin{aligned}
\operatorname{Exp}_{\mathrm{pg}} & =(\text { hours per day/24 hours }) \times((\text { days per month } \mathrm{x} 12 \text { months }) / 365 \text { days }) \\
\operatorname{Exp}_{\mathrm{pi}} & =(\text { hours per day } / 24 \text { hours }) \times((\text { days per month } \times 12 \text { months }- \text { leave days }) / 365 \text { days })
\end{aligned}
$$


Where $\operatorname{Exp}_{p g}$ and $\operatorname{Exp}_{p i}$ represent the exposure of an individual and a group respectively.

The exposure of equipment can be determined as follows:

$$
\operatorname{Exp}_{\mathrm{e}}=(\text { hours per day/24 hours) } \mathrm{x} \text { (days per month } \mathrm{x} 12 \text { months) } \mathrm{x} \text { utilisation }
$$

\subsubsection{Monitoring and evacuation}

Monitoring and evacuation can be a very effective way of reducing the probability of injury or damage to equipment. This concept has been used very successfully in open pit operations using slope stability radar. Suitable monitoring systems which would allow evacuation of personnel safely are being researched and are discussed in Section 3.3. In general, they should be considered to have a very low probability of success when being considered for evacuation. However, in shallow platinum and chrome mines, very large falls of ground invariably provide a warning through the noise during the slow failure of timber elongates and people are evacuated safely. Injuries associated with these large rockfalls are rare for this reason.
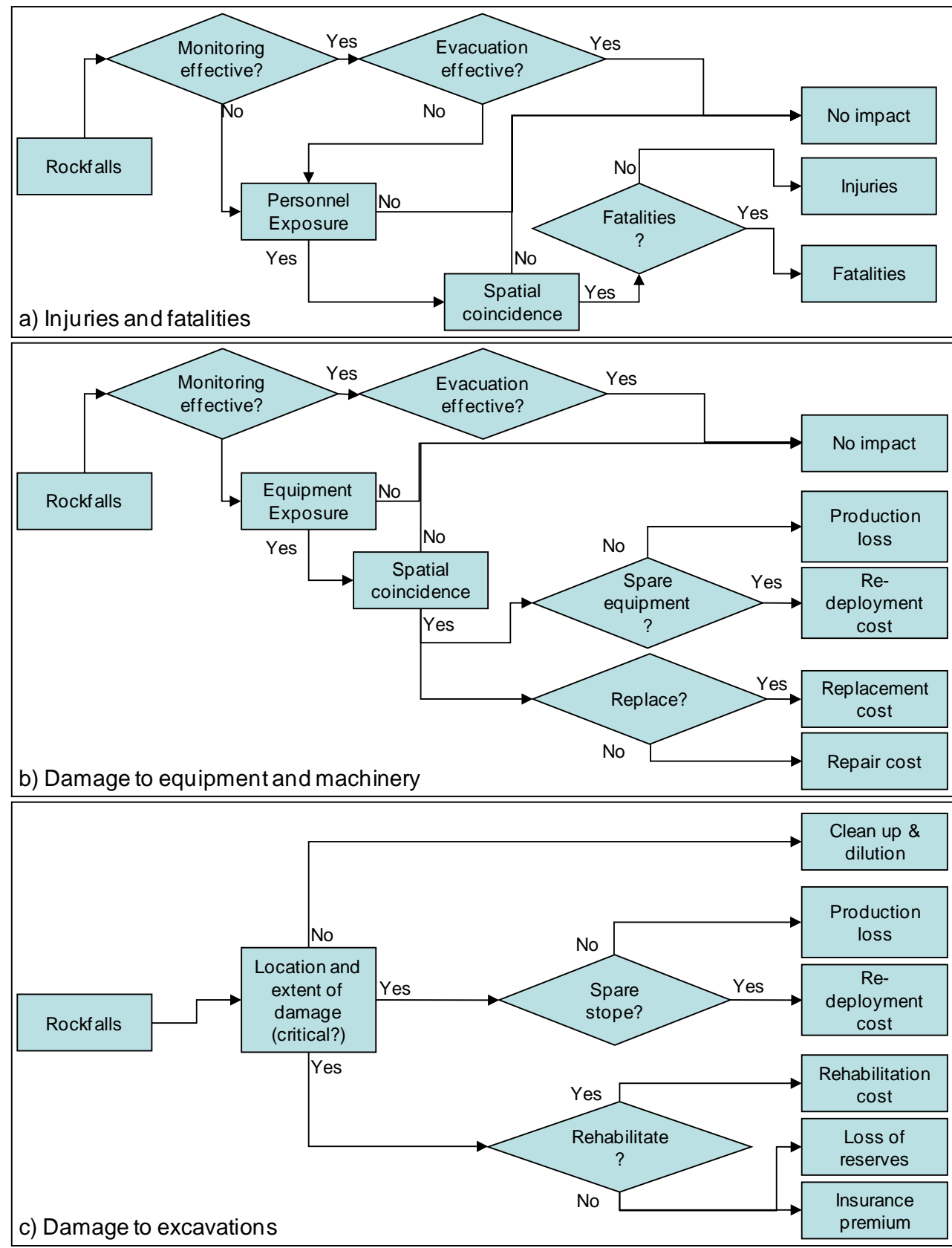

Figure 7 Simplified event trees for a) injuries and fatalities; b) damage to equipment and machinery; c) damage to excavations 


\subsubsection{Determination of spatial coincidence}

Spatial coincidence implies that the rockfall must occur in the same area that people or equipment are present at the time of occurrence of the rockfall. The probability of spatial coincidence is the joint probability of a rockfall occurring in a given area and one or more persons, or an equipment item being present in the same area. The probabilities are multiplied.

Figure 8 shows the spatial relationships for the determination of the probability of a rockfall in given area, one or more persons in a given area, and equipment in a given area. The probability of occurrence of a single rockfall $\left(p_{r}\right)$ is simply the rockfall area $\left(A_{r}\right)$ divided by the area in which the rockfall can occur (stope area, $\left.A_{s}\right)$. For equipment, the probability of equipment being in a given area $\left(p_{e}\right)$ is $A_{e} / A_{s}$, where $A_{e}$ is the area taken up by equipment. If there are several people working in a stope at any one time, more than one person can be injured if the rockfall is large enough. Most significant rockfalls will have an equal or larger area than that occupied by a person and more than one person could occupy this area. It is therefore proposed that a probability of a person being exposed in a given area $\left(p_{p}\right)$ equal to the rockfall area is equal to $A_{r} / A_{x}$, where $A_{x}$ is the area in which people travel and are exposed.

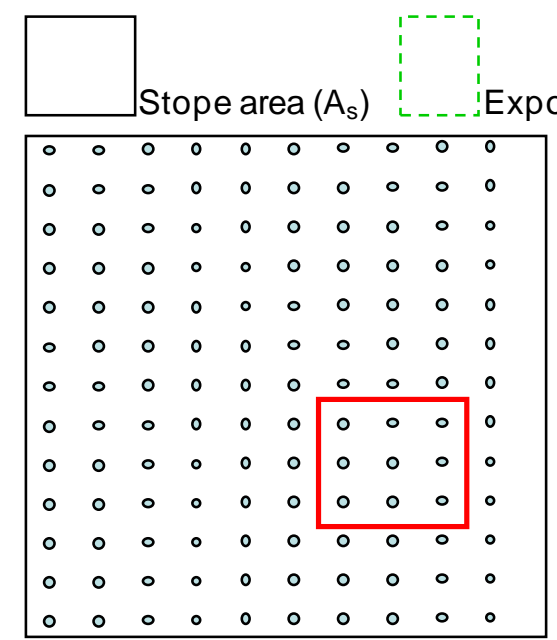

a) Rockfall

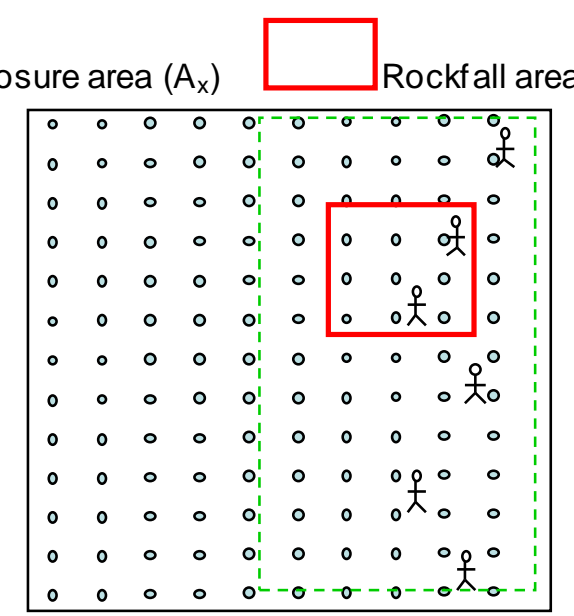

b) Personnel

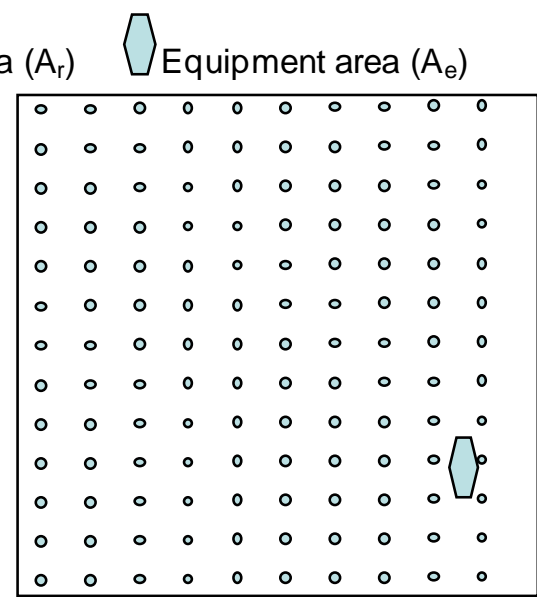

c) Equipment

Figure 8 Spatial coincidence: determination of probabilities for a) rockfall; b) personnel; and c) equipment

Several rockfalls occur in a stope area during one year and several people could possibly occupy a given rockfall area at a time. The probability of $x_{r}$ or more rockfalls occurring in a given area in one year $\left(F_{r}\left(x_{r}\right)\right)$ and the probability of $x_{p}$ or more people occupying a given area at one time $\left(F_{p}\left(x_{p}\right)\right)$ can be determined using the binomial distribution:

$$
F(x)=\sum_{x}^{n} \frac{n !}{x !(n-x) !} p^{x}(1-p)^{n-x}
$$

Where $x=$ the number of occurrences, $p=$ the probability of occurrence and $n=$ the number of trials.

For rockfalls $F_{r}\left(x_{r}\right)$ is a function of $x_{r}$ (number of occurrences of rockfall in a given area), $p_{r}$ and $n_{r}$ (number of rockbursts per annum in the stope area). The probability of one or more rockfalls occurring in one year is $F_{r}(0)$. This value needs to be corrected for $A_{x}$, the area in which people travel. It is multiplied by $A_{x} / A_{s}$.

For persons $F_{p}\left(x_{p}\right)$ is a function of $x_{p}$ (number of persons in a given area), $p_{p}$ and $n_{p}$ the number of people working in the stope.

Spatial coincidence for personnel (groups): $\mathrm{C}_{\mathrm{pg}}\left(\mathrm{x}_{\mathrm{p}}\right)=\mathrm{F}_{\mathrm{r}}(0)\left(\mathrm{A}_{\mathrm{x}} / \mathrm{A}_{\mathrm{s}}\right)\left(\mathrm{F}_{\mathrm{p}}\left(\mathrm{x}_{\mathrm{p}}\right)\right)$

Spatial coincidence for personnel (individual): $C_{p i}=F_{r}(0)\left(A_{x} / A_{s}\right) p_{p}$

Spatial coincidence for equipment: $C_{e}=F_{r}(0) p_{e}$ 


\subsubsection{Severity of damage and injuries}

In an excavation, the extent of damage and the size of rockfall are the same. It is reasonable to assume that the larger the rockfall the more severe the injury or damage to equipment, but with some degree variability. Suitable data has not yet been obtained to quantify the relationship between size of rockfall and severity of damage or injury. Damage costs and the likelihood of fatalities can be determined in proportion to the size of the rockfall once suitable relationships have been established.

\subsection{Calculated example}

For this example, the following assumptions were made:

Number of people in stope, $n_{p}=6$.

$A_{s}=5 \mathrm{~m} \times 20 \mathrm{~m}=100 \mathrm{~m}^{2} ; A_{x}=5 \mathrm{~m} \times 20 \mathrm{~m}=100 \mathrm{~m}^{2} ; A_{e}=5 \mathrm{~m} \times 2.5 \mathrm{~m}^{3}=12.5 \mathrm{~m}^{2}$.

$n_{r}$ and $A_{r}$ values were determined from the frequency distribution in Figure 4. $A_{r}=\pi \mathrm{r}^{2}$, where $r$ is the equivalent rockfall radius bin in Figure 4.

$p_{r}, p_{p}$ and $p_{e}$ were calculated as outlined in Section 5.2.3.

The values of $F_{r}(0)$ were calculated for each equivalent rockfall radius bin using the data in Figure 4 and applying Equation (4), as outlined in Section 5.2.3 and the results are presented in Figure 9. $F_{r}(0)$ was calculated using the actual data and the fitted exponential and power distributions. The resulting probabilities were divided by 1000 to represent the annual probability of occurrence for one stope panel. The fitted distributions were used to take into account the expected frequencies of smaller rockfalls, since these are not reliably recorded. The effect of the larger rockfalls $\left(>50 \mathrm{~m}^{2}\right)$ is reduced and ultimately removed by assuming a low probability of evacuation failure for large rockfalls, which represents reality. The dashed lines represent the unaltered $F_{r}(0)$ curves. The higher frequencies for the smaller rockfalls are taken into account in the results for the fitted distributions.

The values of $F_{p}\left(x_{p}\right)$ with $x_{p}$ from 1 to 6 were calculated for each equivalent rockfall radius bin using Equation (3), as outlined in Section 5.2.3 and the results are presented in Figure 10. The probability of multiple persons being present in a given rockfall area, clearly increases with increasing rockfall area. When the equivalent rockfall radius is greater than $6 \mathrm{~m}\left(113 \mathrm{~m}^{2}\right)$, which is equivalent to $A_{x}$, the probability of all six people being present is $100 \%$.

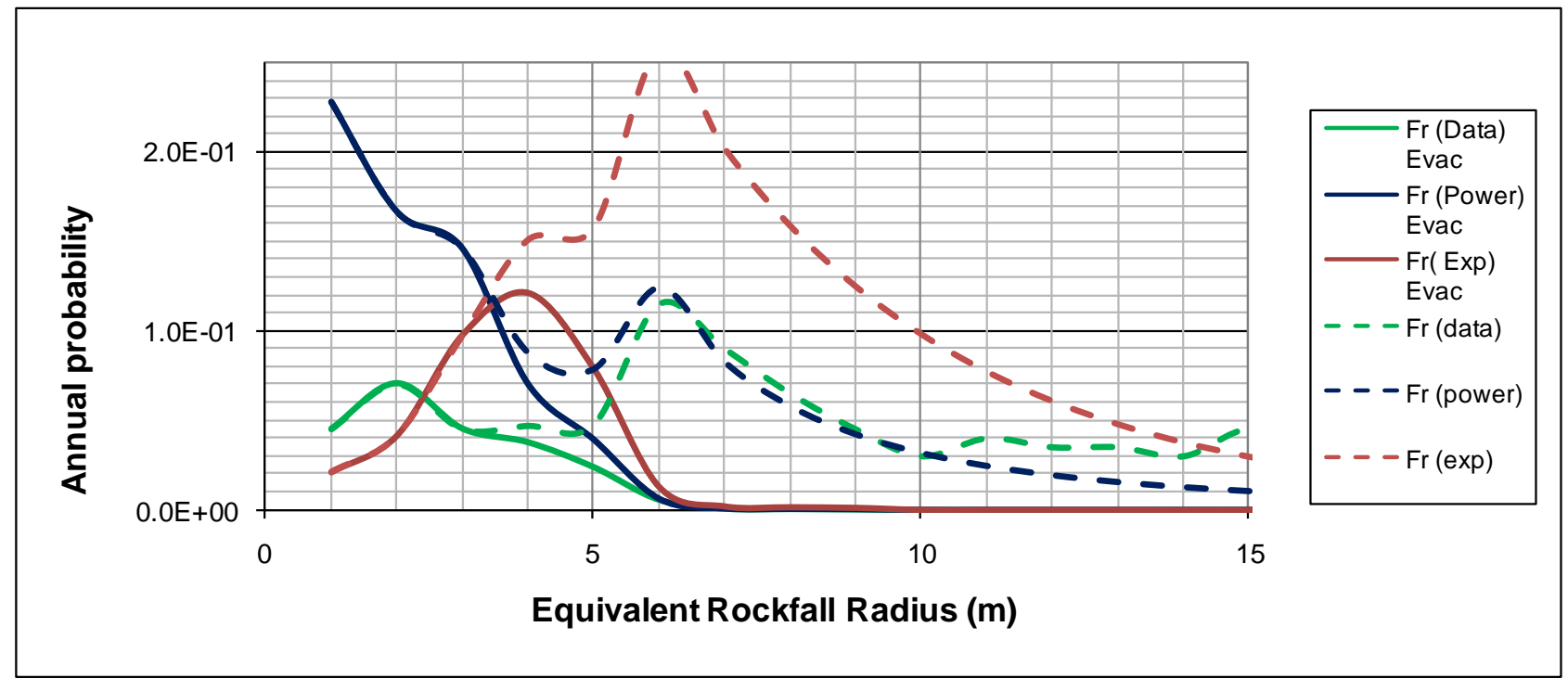

Figure 9 Annual probability of more than one rockfall in a given area, represented by the equivalent rockfall radius, determined using the actual rockfall distribution and the power and exponential fits in Figure 4 (solid lines represent the $F_{r}$ curves $\times$ the probability of a failed evacuation) 


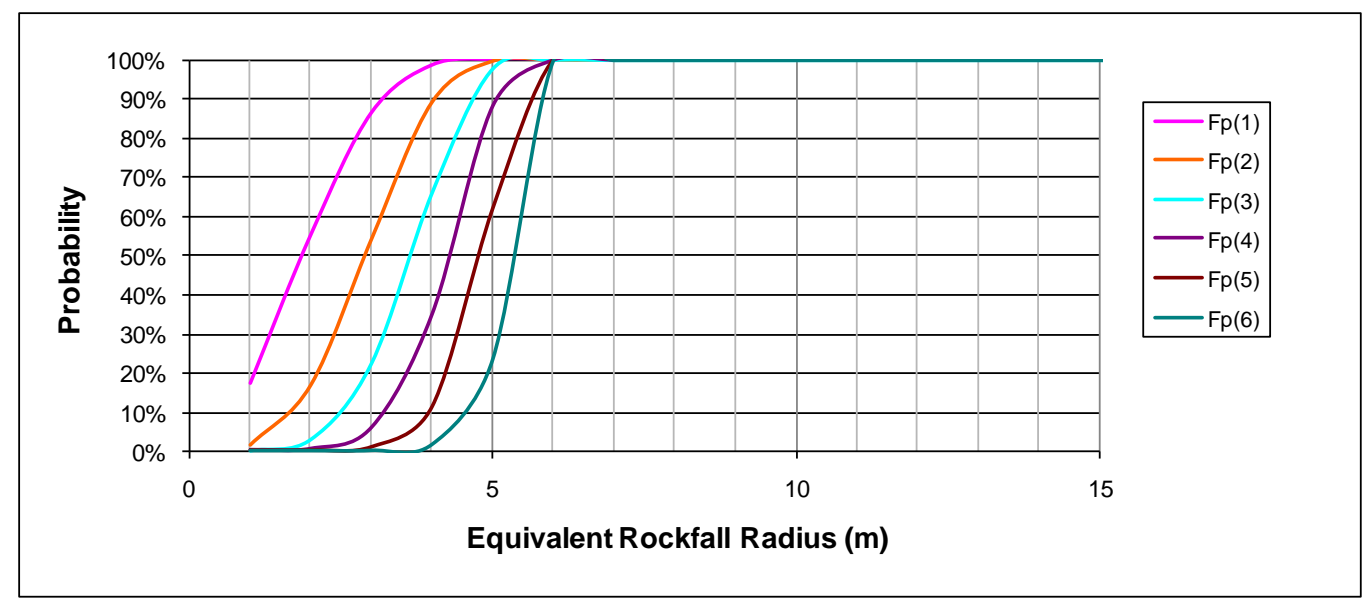

Figure 10 Probability of $x_{p}$ or more people exposed in a given area represented by the rockfall radius

If exposures $\left(\operatorname{Exp}_{p g}=20 \%\right.$ and $\left.\operatorname{Exp}_{e}=42 \%\right)$ are used, the probability of occurrence of injuries $\left(\operatorname{Inj} j_{g}\left(x_{p}\right)\right)$ and $I n j_{i}$ (group and individual), and damage to equipment (Damage) can be determined for different rockfall sizes, using Equations (1) to (7) as follows:

$$
\begin{gathered}
\operatorname{In}_{\mathrm{jg}}\left(\mathrm{x}_{\mathrm{p}}\right)=\operatorname{Exp}_{\mathrm{pg}} \times \mathrm{C}_{\mathrm{pg}}\left(\mathrm{x}_{\mathrm{p}}\right) \\
\operatorname{Inj}_{\mathrm{i}}=\operatorname{Exp}_{\mathrm{pi}} \times \mathrm{Cp}_{\mathrm{pi}} \\
\text { Damage }=\operatorname{Exp}_{\mathrm{e}} \times \mathrm{C}_{\mathrm{e}}
\end{gathered}
$$

The probability of injuries and damage for different rockfall radii, calculated using the fitted power distribution for rockfall size, are presented in Figure 11.

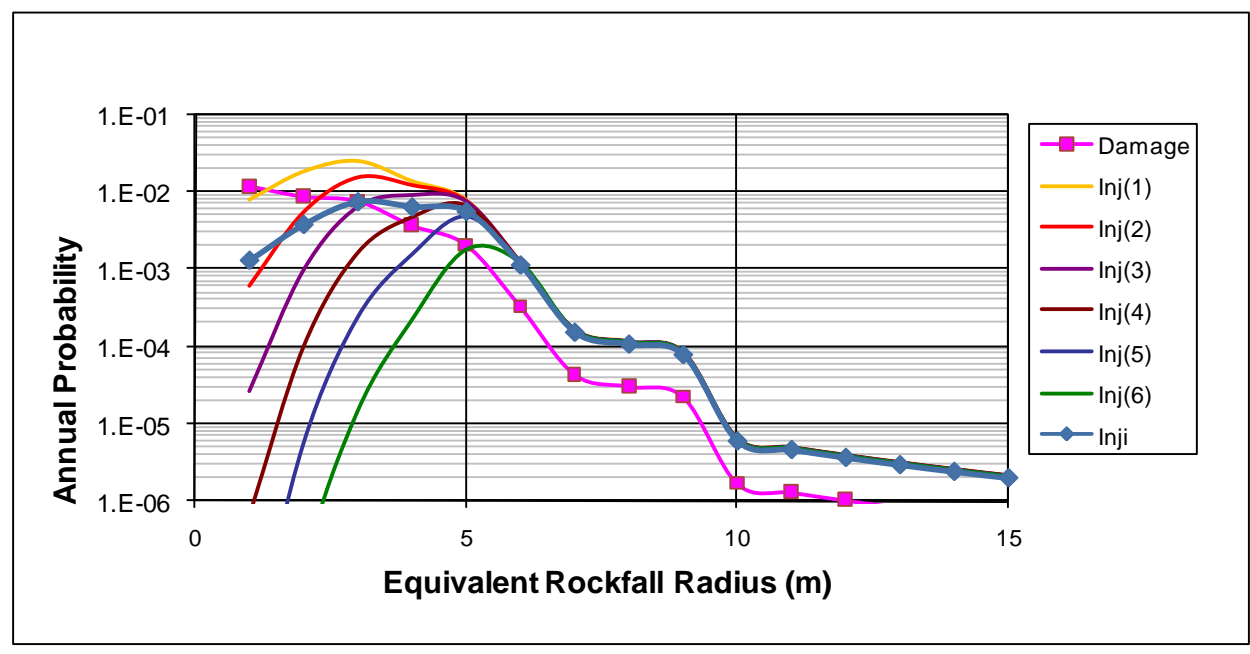

Figure 11 Probability of injuries and equipment damage for different rockfall radii

If the damage costs are known for different rockfall sizes, it is possible to calculate the expected cost of damage using the results of Figure 11.

The overall probability of occurrence of injuries is the sum of the probabilities of occurrence for each equivalent rockfall radius. At this stage the ratio of fatalities to injuries for different size rockfalls is not known and therefore, a constant rate was used. The rate of one fatality to 25 injuries was determined from mine accident statistics. The F-N curves can be determined and these are plotted in Figure 12. The results for groups of personnel (panel crews) and individuals are plotted. The expected F-N curve for the entire population (1000 stope panels) is obtained by multiplying the group results by 1000 stope panels. The fitted rockfall size distributions correlate better with actual mine accident statistics. The steeper F-N curve provided by the power fit is more realistic. 


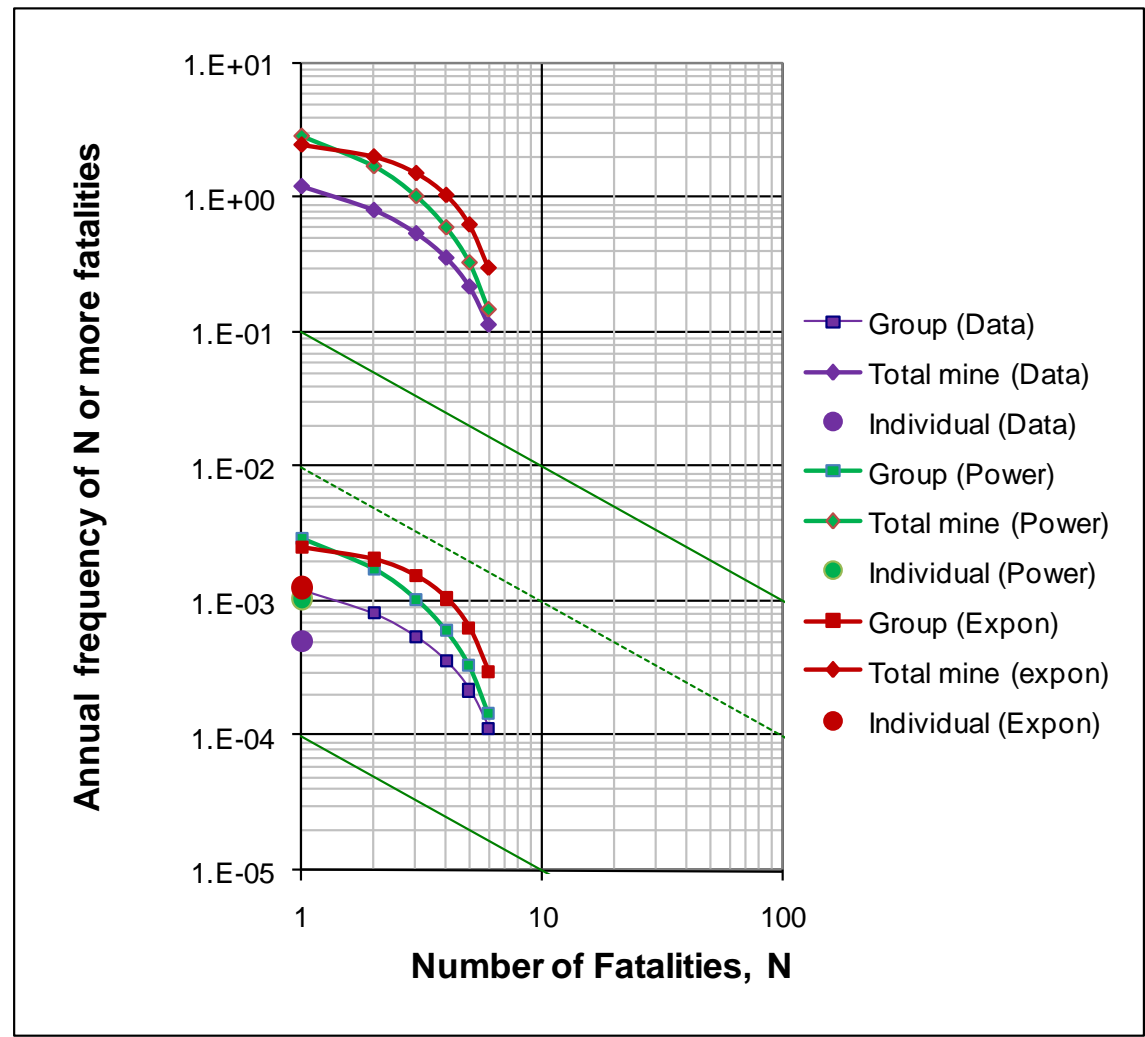

Figure 12 Results plotted on the F-N graph

\section{Conclusions}

The preliminary model can be used to calculate the expected number of injuries and fatalities from a distribution of rockfall sizes, but requires further refinement and a more comprehensive analysis of the available rockfall accident data.

Analytical models can be used to calculate the probability of occurrence of rockfalls and programs like JBlock can simulate distributions of rockfall sizes. These models are being developed further and will allow comparisons of different support systems and safety strategies.

The F-N graph can be used as a tool for evaluating the annual frequency of occurrence of fatal injuries. For benchmarking purposes and setting of targets, the individual risk should be used. The risk of maximally exposed workers must be reduced. Individual risk is also not dependant on population size, and therefore unambiguous comparisons can be made. F-N curves can be determined for groups of workers in concentrated areas, such as stope panel crews. This allows the risk of multiple fatalities to be evaluated. It can be scaled up for any population size to predict the expect number of accidents per annum to evaluate the societal risk, which affects public perception and can lead to stakeholder resistance or industrial action.

The expected number of occurrences of damage to equipment can be evaluated for a distribution of rockfall sizes. The expected costs associated with equipment repair, loss of production and loss of reserves can be evaluated. Further work is required to establish the severity of damage and potential for loss of production through analysis of case studies. It is anticipated that it will be possible to quantify the benefits of safety spending in order to provide an additional motivation for improved safety.

\section{Acknowledgements}

The authors would like to thank the Mine Health and Safety Council (MHSC) for the funding of this research and permission to publish this paper.

The management of Lonmin and Impala Platinum are thanked for providing rockfall data for this research. 
Lawrence Rwodzi is thanked for compiling rockfall data and information for the direct and indirect consequences of rockfalls and event trees.

Olaf Goldach is thanked for compiling the list of monitoring systems, which were summarised for this paper.

The attendees of the two project workshops (too many to list individually) are thanked for their input.

Dave Roberts, Dick Stacey, Luis-Fernando Contreras, Graham Howell, Essie Esterhuizen and Oscar Steffen are thanked for taking the time to read the draft and offer suggestions to improve the final paper.

\section{References}

Barton, N., Lien, R. and Lunde, J. (1974) Engineering classifications of rock masses for the design of tunnel support. Rock Mechanics. 6 (4), pp. 189-236.

Brady, B.H.G. and Brown, E.T. (2006) Rock Mechanics for Underground Mining, third edition. London, Chapman and Hall, pp. 230-235.

Brink, A.v.Z and Roberts, M.K.C. (2007) Early Warning and/or Continuous Risk Assessment of Rockfalls in Deep South African Mines. Fourth International Seminar on Deep and High Stress Mining, Australian Centre for Geomechanics, Perth, Australia, November 2007, pp. 437-450.

Contreras, L.F., LeSeur, R. and Maran, J. (2006) A case study of risk evaluation at Cerrejon mine. Proceedings International Symposium on Stability of Rock Slopes in Open Pit and Civil Engineering, Cape Town, p. 202.

Diederichs, M.S. and Kaiser, P.K. (1999) Stability of large excavations in laminated hard rock masses: the voussoir analogue revisited. Int. J. of Rock Mech. and Mining Sciences. Vol. 36, pp. 97-117.

Dunn, M., Earl, P.J. and Watson, J. (2008) Support design using probabilistic keyblock methods. 6th International Symposium on Ground Support in Mining and Civil Engineering Construction, Cape Town, South Africa.

Esterhuizen, G.S. (2003) JBlock User's Manual.

Esterhuizen, G.S. and Streuders, S.B. (1998) Rockfall hazard evaluation using probabilistic keyblock analysis. Jour. S. Afr. Inst. Min. Metall., Vol. 98, No. 2, pp. 59-63.

Goodman, R.E. and Shi, G. (1985) Block theory and its application in rock engineering. Prentice Hall, 338 p.

Grenon, M. and Hadjigeorgiou, J. (2003) Open stope stability using 3D joint networks. Rock Mech. Rock Engng. 36 (3), pp. 183-208.

Harr, M.E. (1987) Reliability based design in civil engineering. Mc Graw-Hill, New York, pp. 205-220.

Hutchinson, D.J. and Diederichs, M.S. (1998) Cable bolting in underground mines. BitTech Publishers Ltd. Richmond, British Columbia. ISBN 0-921095-37-6, pp. 221-240.

Joughin, W.C., Armstrong, R. and Pethö, S.Z. (2006) Assessment of the stability of longhole stope backs at South Deep. Proceedings of SANIRE 2006 - Facing the challenges, Rustenberg.

Laubscher, D.H. (1990) A Geomechanics classification system for the rating of rock mass in mine design. J.S. Afr. Inst. Min. Metall. Vol. 90, No. 10, pp. 257-273.

Piper, P.S. and Malan, D.F. (2008) The in-situ performance of elongate support - myths and realities. 6th International Symposium on Ground Support in Mining and Civil Engineering Construction, Cape Town 2008, pp. $299-316$.

Potvin, Y. (1998) Empirical stope design in Canada. PhD Thesis, University of British Columbia.

Potvin, Y. and Hadjigeorgiou, J. (2001) The stability graph method for open stope design. In W.A. Hustrulid and R.L. Bullock (editors), Underground mining methods: engineering fundamentals and international case studies. Society for Mining Metallurgy and Exploration, Inc SME, pp. 513-520.

Rosenblueth, E. (1975) Point estimates for probability moments. Proceedings of the National Academy of Sciences of the United States of America Vol. 72 No. 10, pp. 3812-3814.

Stacey, T.R. (2007) Is Rock Engineering addressing risk appropriately? SANIRE Free State Symposium - Re-defining the boundaries Part II, Vereeniging, South Africa, pp. 73-83.

Stacey, T.R., Terbrugge, P.J. and Wesseloo, J. (2007) Risk as a Rock Engineering design criterion. In Challenges in Deep level mining. Y. Potvin, J. Hadjigeorgiou, T.R. Stacey (editors), Australian Centre for Geomechanics, Perth, Australia, pp. 17-23.

Swart, A.H., Stacey, T.R., Wesseloo, J., Joughin, W.C., Le Roux, K., Walker, D. and Butcher, R. (2000) Investigation of factors governing the stability/instability of stope panels in order to define a suitable design methodology for near surface and shallow mining operations. Safety in Mines Research Advisory Committee (SIMRAC) final project report OTH501.

Terbrugge, P.J., Wesseloo, J., Venter, J. and Steffen, O.K.H. (2006) A risk consequence approach to open pit slope design. Jnl. S.Afr. Inst. Min. Metall., Vol. 106, pp. 503-511. 